\title{
The Irpinia (Italy) 1980 earthquake: waveform modelling of accelerometric data and macroseismic considerations
}

\author{
Franco Vaccari $\left({ }^{1,2,3}\right)$, Paolo Harabaglia $\left({ }^{1,2,4}\right)$, Peter Suhadolc $\left({ }^{1,2}\right)$ and Giuliano F. Panza $\left({ }^{1,2}\right)$ \\ $\left(^{(}\right)$Istituto di Geodesia e Geofisica, Università di Trieste, Trieste, Italia
$\left(^{2}\right)$ International Institute for Earth, Environmental and Marine Sciences and Technologies $\left({ }^{1,2}\right)$
}

(3) CNR, Gruppo Nazionale Difesa dai Terremoti, Roma, Italia

$\left({ }^{4}\right)$ DEAPS - MIT, Cambridge, USA

\begin{abstract}
A detailed investigation, based on accelerometric and macroseismic data of the Irpinia 1980 event, is presented. The study is based on the use of synthetic seismograms, computed by the modal summation technique, and its purpose is to retrieve information concerning the rupturing process.

Initially, for a first rough analysis, the $40 \mathrm{~s}$ sub-event has been neglected. The recorded accelerograms at the stations of Auletta, Bagnoli Irpino, Bisaccia, Brienza, Calitri and Sturno have been low-pass filtered with a cut-off frequency of $10 \mathrm{~Hz}$, and the rupturing process has been modeled, by a trial-and-error technique, with twelve An auto properly distributed in space and time.

frequencies not higher than $1 \mathrm{~Hz}$. A very good fuccessively applied to the whole observed waveforms, for the obtained rupturing model is in gross good fit has been achieved between observations and synthetics, and Finally, the information about th gross accord with what retrieved by the first rough analysis.

which have been compared with the obring process has been used in order to compute synthetic isoseismals, also included in the computation, its influee macroseismic field. Since the source radiation pattern has been
\end{abstract}

\section{Introduction}

It is well known that the recording of the Irpinia 1980 earthquake has been modeled with quite complicated source models (e.g., Westaway and Jackson, 1987; Bernard and Zollo, 1989). Relatively good strong ground-motion recordings were obtained (Berardi et al., 1981), though it is not an easy task to retrieve the extended source model from these data. Here we present an updated review of several works we have published on the 1980 Irpinia event.

In sect. 1 we discuss the results of a trial-anderror procedure, aimed at the reconstruction of the rupturing process at the source, which makes use of the deterministic computation of synthetic signals at high frequencies (cut-off $10 \mathrm{~Hz}$ ). A rough fit of the accelerometric data is obtained for the six stations closest to the epicentral area.

Section 2 deals with waveform fitting of low- pass filtered data (cut-off $1 \mathrm{~Hz}$ ). The source model is imaged through an inversion of the released seismic moment. From this model a very good agreement is obtained between recorded and synthetic accelerations, both in waveform and amplitude. The resolving power of the data is also discussed.

Finally, in sect. 3, the observed macroseismic field is analysed and its main characteristics are reproduced by means of synthetic isoseismals. The important role played by the source geometry and orientation is demonstrated.

\section{Envelope fitting at high frequencies $(10 \mathrm{~Hz}$ cut-off)}

A detailed description of the fitting procedure has been published by Suhadolc et. al., 1988a and Vaccari et al., 1990a). 
The recorded ENEA-ENEL accelerograms (Berardi et al., 1981) are shown in fig. 1. Only the first $30 \mathrm{~s}$ are plotted and have been used in the analysis since the $40 \mathrm{~s}$ sub-event, easily recognizable in some of the original recordings, is quite well separated from the previous ones and is generally accepted to be quite an independent sub-event, occurring on a secondary fault.

A trial-and-error procedure is adopted in order to select, among a quite wide distribution of possible solutions, the one which can explain the main features of the accelerometric data with a low number of point sources. Each point source can be considered to represent a breaking asperity (Kanamori and Stewart, 1978), but the interpretation in terms of the barrier model (Das and Aki, 1977; Aki, 1979) is equally possible. At first, thirteen evenly spaced locations have been selected along the fault; subsequently three more have been added near the Brienza station (see fig. 2). The spacing of these locations, hereafter called epicentres, is $5.7 \mathrm{~km}$. A total of 10 hypocentral depths between 2 and $17.5 \mathrm{~km}$ has been considered for each epicentre, and the corresponding theoretical accelerations have been computed (Panza, 1985; Panza and Suhadolc, 1987; Florsch et al., 1991) at the six stations under consideration by the modal summation technique. The structural model (fig. 3) used to construct the synthetics is derived from the «Model A» proposed by Del Pezzo et al. (1983), and have been kept constant for all the stations. A time delay and a relative weight have been subsequently assigned to each point source, in order to simulate with a time sequence the evolution and size of the rupturing process.

To be kept in the global source model, a point source has to satisfy the following conditions: 1 ) its relative time delay, measured from the nucleation time of the fracture (first point source of the sequence), together with the distance and time shift from the nearest point source, must be compatible with a sub-shear rupture velocity. There are no exceptions to this rule; 2) the amplitudes measured at the six stations, after assigning a weight to the point source, must be in agreement with the observed ones; since the local site effects are not taken into account in the computation of the synthetic accelerograms, some tolerance is allowed for this rule.
The synthetic signals of fig. 4 are the final result of the trial-and-error procedure. Some caution is necessary in the interpretation of the obtained sequence of point sources, since from the representation theorem we know that also the effect of lateral variations can be modeled with point sources. In any case, we consider it quite remarkable that even neglecting lateral variations, the synthetic signals of fig. 4 have been obtained superimposing the effect of only 12 point sources, chosen according to the above-mentioned conditions. A vertical section of the retrieved source model is given in fig. 5, while the temporal evolution of the rupturing process is shown in fig. 6 .

Since the aim of this modelling is not a peakto-peak matching, but rather an envelope fit, a check on the quality of the result can be given by comparing the amplitude spectra of observed and synthetic records. Vaccari et al. (1990a) showed that, even by considering a few point sources with relatively simple time functions, the synthetic spectra have the tendency to reproduce the general features of the observed ones.

Even if the source model is intended to be only a rough estimate aimed at identifying the areas where most of the slip occurred, it seems possible to outline the overall initial rupturing process as propagating bilaterally, with a sub-sonic velocity, possibly along the path schematized by the dotted line in fig. 5. The distribution of point sources simulating the propagation upwards and to the NW from the nucleation point seems to be quite regular both in space and time. This part of the fracturing process can, therefore, be assumed to be almost continuous.

The southeastern portion of the fault, on the other hand, is not so well linked in space and time with the central fracture process and could be assumed to represent an almost «independent» event. The later parts of the strong-motion records are reproduced by means of some shallow point sources, with varying seismic moment, simulating the stopping of the rupture below or within the upper sedimentary cover and, very likely, some effect of the lateral heterogeneities.

The waveform fitting can be obviously improved considering a large number of point sources but, at present, we consider that a close waveform matching at frequencies higher than a few hertz is not relevant to the understanding of 


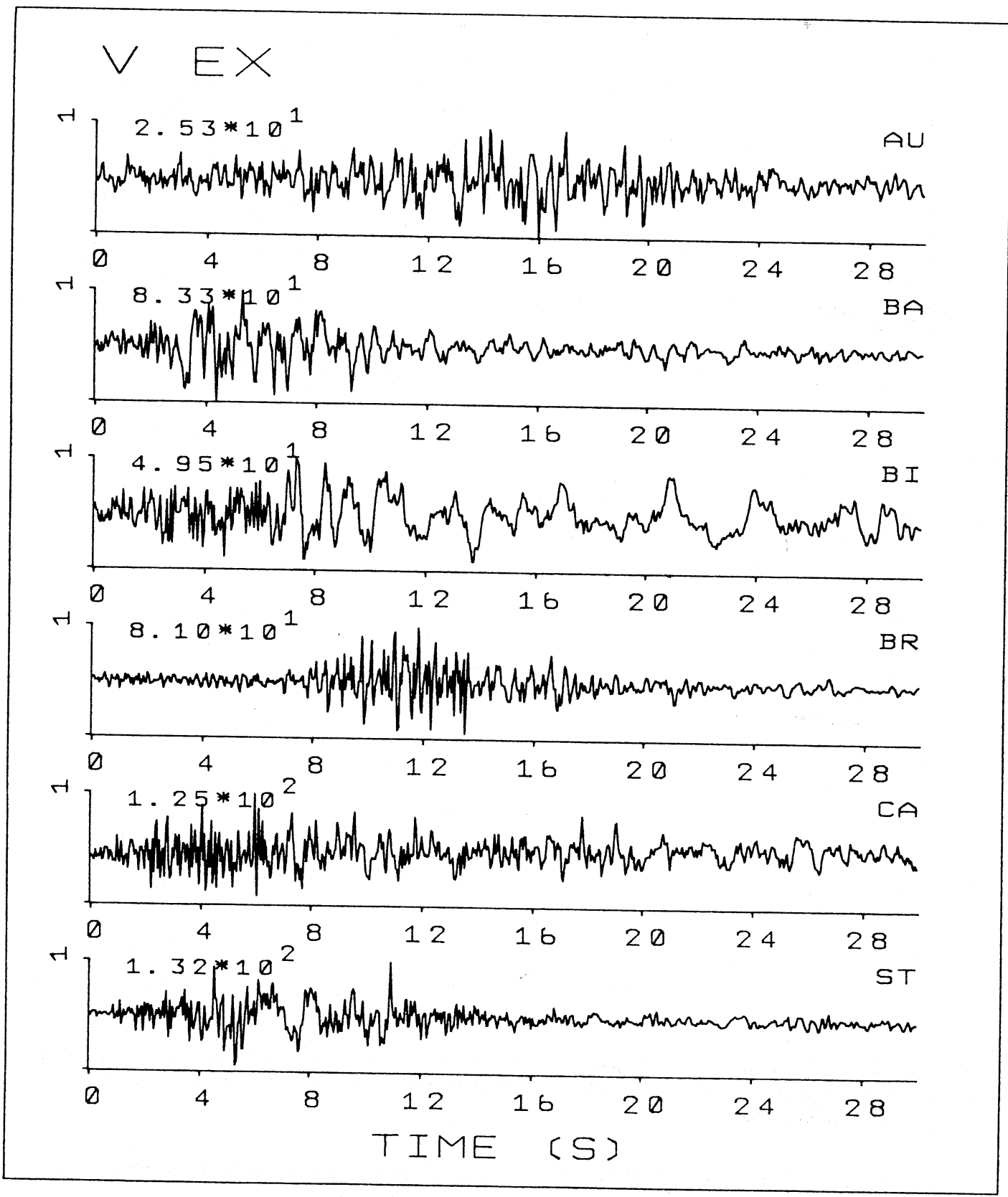
Fig. 1. Observed vertical accelerations (first $30 \mathrm{~s}$ ) at the six considered stations, after Gaussian filtering with
cut-off frequency at $10 \mathrm{~Hz}$. 


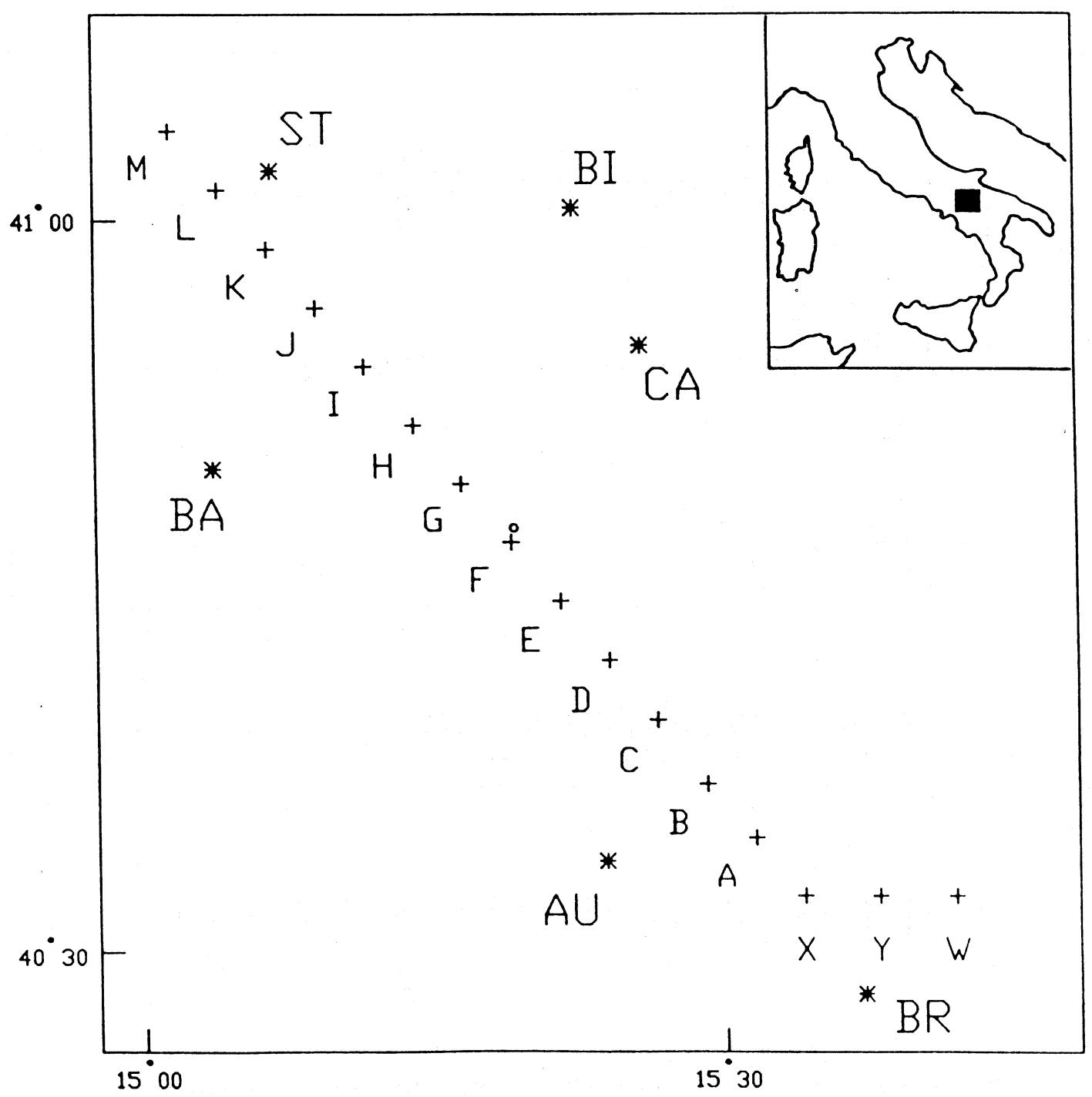

Fig. 2. Map of the epicentral area. Crosses indicate the epicentres used in the construction of the synthetic signals. The six considered stations are: Auletta (AU), Bagnoli Irpino (BA), Bisaccia (BI), Brienza (BR), Calitri (CA) and Sturno (ST).

the source process. In fact, using high-frequency information in a deterministic way, in order to model wave propagation in $2 \mathrm{D}$ or $3 \mathrm{D}$ media, requires both a better understanding of the highfrequency behaviour of earthquake rupturing and the knowledge of the structural parameters to the scale of the involved wavelengths.

\section{Waveform inversion at low frequencies (1 Hz cut-off)}

A closer waveform match is therefore attempted after low-pass filtering of the recorded data. Throughout the process of inversion of the ENEA accelerograms we have singled out some 


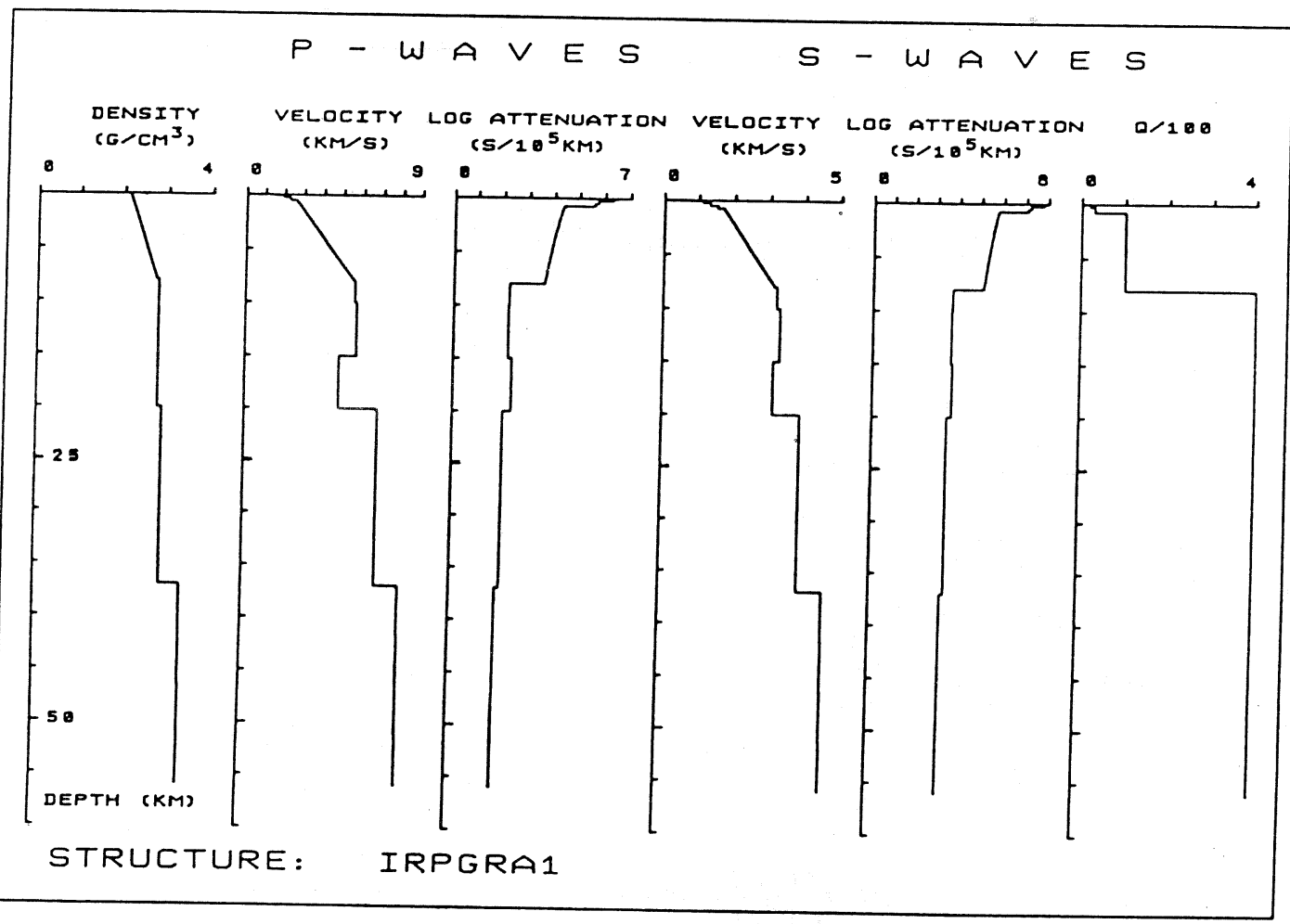
Fig. 3. Structural model, describing the variations with depth of the density, elastic and anelastic parameters,
used in the computation of synthetic accelerograms.

features of the source on which we have great confidence, and, in doing so, we have also measured the resolving power of these accelerograms.

The method (Harabaglia et al., 1987) iterates through a series of loops. In the outer loop we define the spatial location of each fault, we discretize it as a dense grid of point sources and assign an average slip direction. For each point source, we compute the synthetic accelerograms relative to all the network sites, assuming a normalized moment of 1 dyne $\mathrm{cm}$. The actual computation is performed through a modal summation technique. The $i$-th synthetic record can be expressed as

$$
s_{i}(t)=S_{j} m_{j} a_{i j}\left(t-t_{j}\right)
$$

where $a_{i j}$ is the synthetic accelerogram for the $j$-th point source, $m_{j}$ is the seismic moment and $t_{j}$ is the time delay from the nucleation or, in a broader sense, from any reference time. Such a problem is highly nonlinear. Attempts to linearize (1) fail since the derivatives with respect to time and the derivatives with respect to the seismic moment are nonhomogeneous quantities and their relative weight is unknown. To solve the problem in the least-square sense we had to damp the time perturbations, requiring the time shift to be smaller than the dominant period of the signal. Under these assumptions, the inversion for the rupturing process becomes meaningless since the difference between starting and final model will be negligible. Therefore we decided to introduce a new loop, fixing the time parameters and defining different models with various rupture velocities expressed as percentage of the $S$-wave velocity. Then, for each of these models, we can solve a much simpler linear problem in the form

$$
A m=d
$$




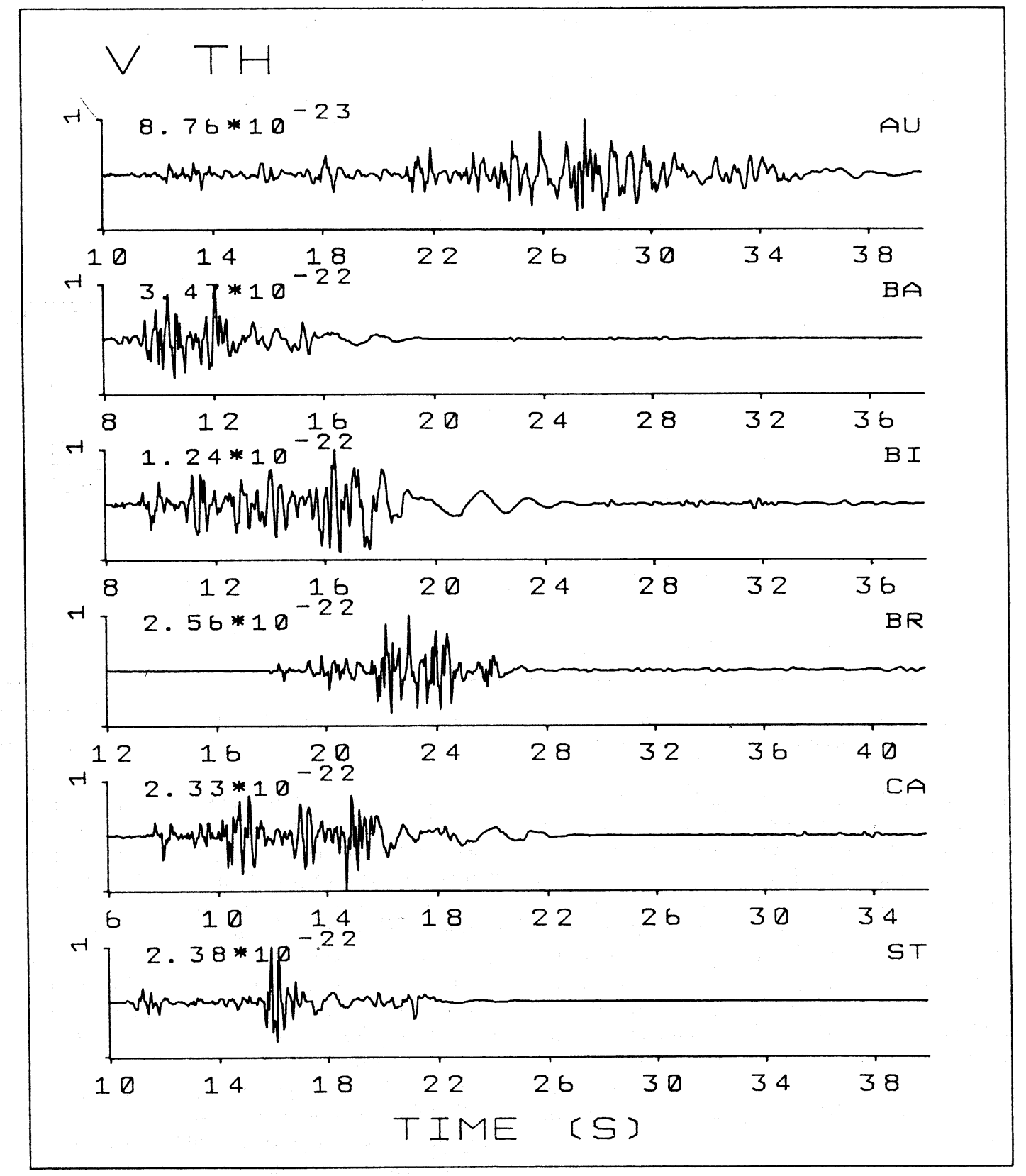

Fig. 4. Synthetic accelerations to be compared with the observed ones, shown in fig.1. Cut-off frequency at $10 \mathrm{~Hz}$. 


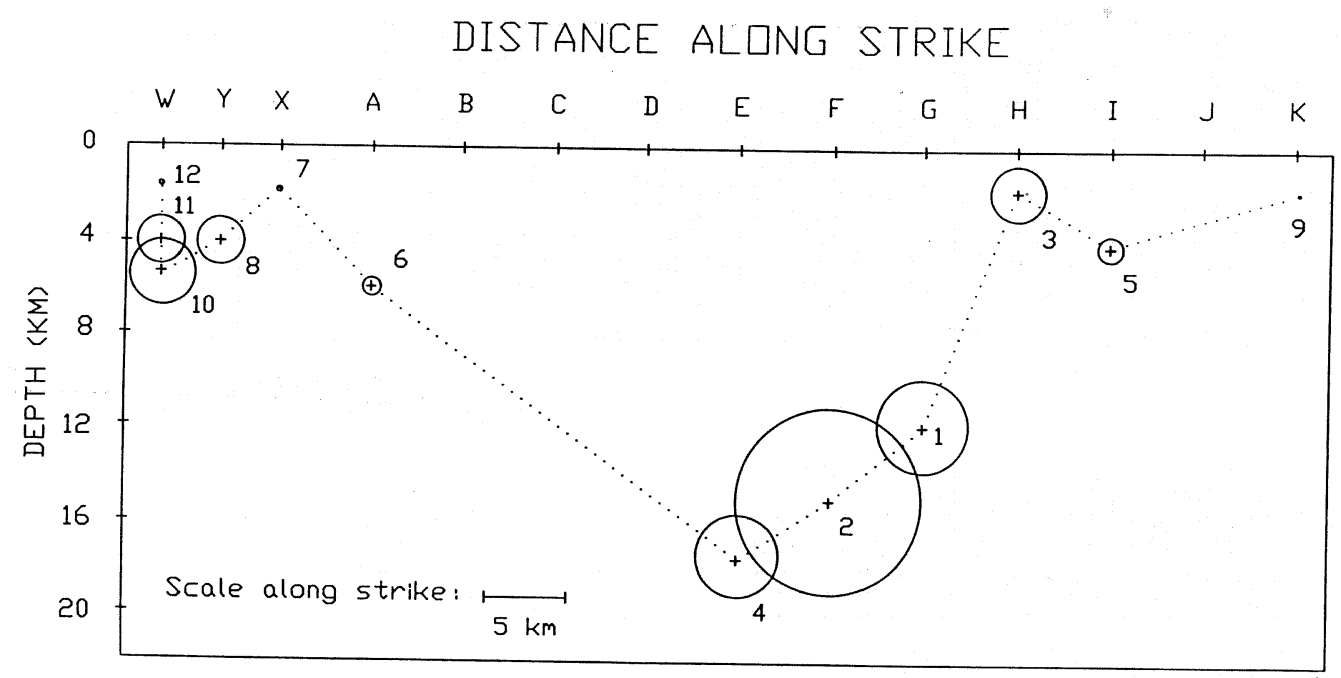

Fig. 5. Space distribution of the point sources used in the construction of the synthetic accelerations.

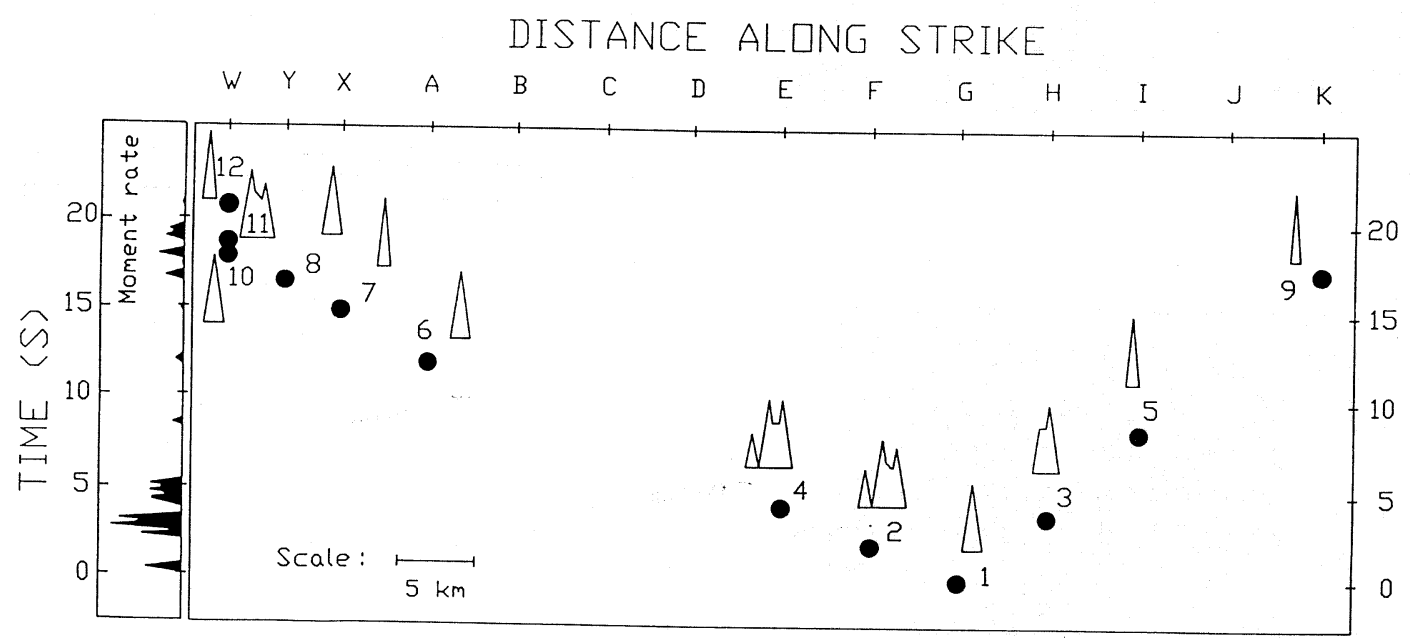

Fig. 6. Space-time distribution of the twelve point sources shown in fig. 5 .

applying the conjugate gradient technique (Press et al., 1986). In this way, we can evaluate several different models and choose the «best» ones following several criteria. Models that do not reproduce certain phases are preferred to models that produce extra ones. This is because our simplified Earth model cannot account for lateral arrivals, diffractions, etc. Only the causality constraint was put on the parameters, but models with a percentage of negative seismic moment (equivalent to backslip) exceeding 5 were discarded. We also normalize the records according to their maximum amplitude. This is equivalent to weighting a record in proportion to its duration. We do so because a short and compact signal generally means that the source is nearby and our algorithm is valid only a few wavelengths away from the source (Panza et al., 1973; Panza, 1985; 

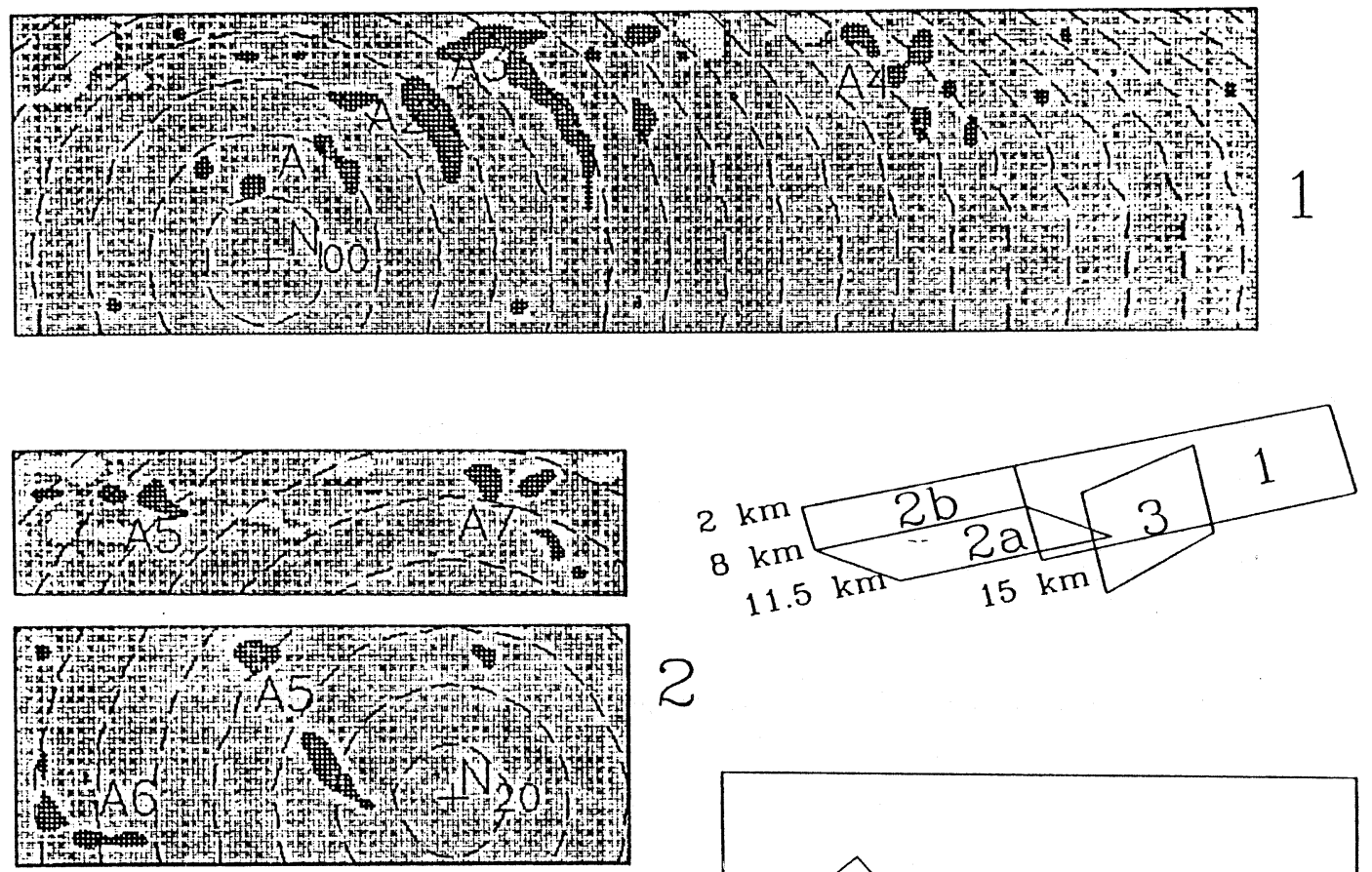

\section{2}

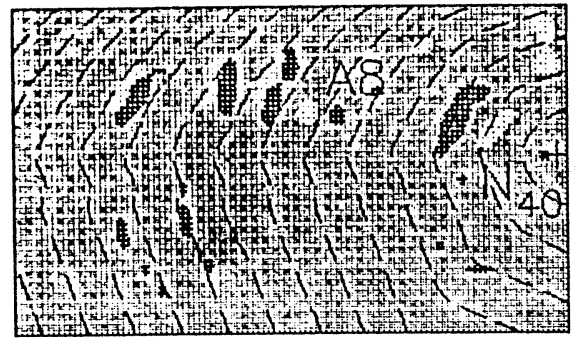

3

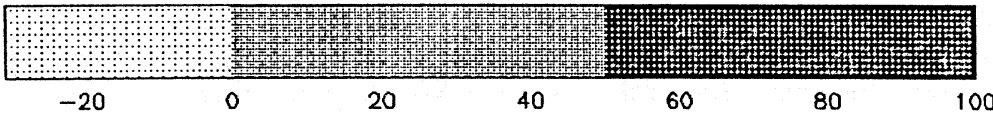

Fig. 7. Distribution of moment release along the faults. The moment is normalized to 100 by the maximum estimated value $\left(3 \times 10^{23}\right.$ dyne $\left.\mathrm{cm}\right)$. Dashed lines represent the rupture front at $1-\mathrm{s}$ intervals. The spatial orientation of the faults is also shown. The total seismic moment released is $1.13 \times 10^{26}$ dyne $\mathrm{cm}$, and the total average slip is $35 \mathrm{~cm}$. Seismic moment and average slip associated with each fault are given in table I. $(+)$ Nucleation points; $(*)$ stations. 


\begin{tabular}{lcc}
\hline \hline Fault & $\begin{array}{c}M_{0} \\
(\text { dyne cm) }\end{array}$ & $\begin{array}{c}\text { Slip } \\
(\mathrm{cm})\end{array}$ \\
\hline 1 & $0.56 \times 10^{26}$ & 35 \\
$2 \mathrm{a}$ & $0.10 \times 10^{26}$ & 47 \\
$2 \mathrm{~b}$ & $0.19 \times 10^{26}$ & 19 \\
3 & $0.28 \times 10^{26}$ & 40 \\
TOT. & $1.13 \times 10^{26}$ & 35 \\
\hline
\end{tabular}

Table I. Seismic moment $M_{0}$ and average slip associated with each of the four faults shown in fig. 7. The global seismic moment is $1.13 \times 10^{26}$ dyne $\mathrm{cm}$, while the maximum seismic moment associated with a single-point source is $3.0 \times 10^{23}$ dyne $\mathrm{cm}$.

Panza and Suhadolc, 1987).

We have evaluated several hundreds of source models differing in the fault location, slip direction and time history, and we have also performed tests against synthetic data. On the basis of our experience, we believe that the fault strike does not vary by more than $3^{\circ}$ in either direction for the long main fault and $8^{\circ}$ for the short one (see fig. 7). We cannot say the same for dip and slip direction: the first can be affected by uncertainties of up to $30^{\circ}$ and the latter up to $60^{\circ}$. Nevertheless, we have seen that we can normally recover the location of the centre of mass of an asperity within about $3 \mathrm{~km}$ and a couple of seconds, even for Earth models with $S$-wave velocities differing on average by as much as $0.5 \mathrm{~km} / \mathrm{s}$. Whenever there is a misparametrization, the inversion will lead to defocusing of the model and eventually to a broadening of the asperities. For this reason we have greater confidence in the location of the asperities and to a certain extent in their size, but we do not believe in their predicted shape. Finally, there is another effect that counteracts the previous one: whenever there are two asperities with the same epicentral location but different depth, the shallower one will mask the effect of the deeper one, as long as the shallower asperity has a moment at least 0.1 times that of the deeper. It is a well-known fact that a rupture normally nucleates at the bottom of a fault and then usually propagates unilaterally upwards (King, 1986). Unfortunately, this means that as the rupture progresses and reaches the surface, using strong-motion data we can only see shallow features and we miss the possibility to study the behaviour of the fault at depth. Therefore, although most of our models do not show any significant energy release at depth, there is no reason to believe that this is true. It just means that the resolving power of the accelerograms is not sufficient, or, in other words, that the solution involving the features of the deeper part of the fault is in the nullspace of the matrix A. We plan to discuss this detail in a future article on the estimation of the ground motion during an earthquake. Here we want to emphasize that although strong-motion data do not contain the information about the source as a whole, they can single out those features that are primarily responsible for the destructive ground motion.

The data we considered in our inversion are the vertical components of the 6 nearest stations of the ENEA network, namely Auletta, Bagnoli Irpino, Bisaccia, Brienza, Calitri and Sturno. We applied a Gaussian filter with a cut-off frequency of $1 \mathrm{~Hz}$. The structural model we used is the same adopted by Vaccari et al. (1990a) (see fig. 3).

There is still some disagreement between various authors on the number of faults involved in the rupturing process (Westaway and Jackson, 1987; Bernard and Zollo, 1989; Pantosti and Valensise, 1990): our model has four faults (fig. 7) and the comparison between synthetic accelerograms resulting from it and the observed ones is shown in fig. 8 .

A little disagreement still exists on the nucleation site and the strike of the main fault. Following Vaccari et al. (1990a), we place the nucleation point at $40^{\circ} 49^{\prime} 45^{\prime \prime} \mathrm{N}$ and $15^{\circ} 17^{\prime} 30^{\prime \prime} \mathrm{E}$ (depth $12 \mathrm{~km}$ ), slightly to the north of Westaway and Jackson's solution (1987). The strike angle is $320^{\circ}$ and the dip angle is $70^{\circ}$ (dipping NE). Since the slip direction is not easily resolvable, we fixed it to $270^{\circ}$ for all the faults. Along the main fault, we can locate four major asperities (A1 to A4 in fig. 7). The first three can be easily associated with the surface faulting seen by Pantosti and Valensise (1990) and with the model proposed by Westaway and Jackson (1987). The last asperity, A4, is placed near Sturno.

Unfortunately, Sturno is the only record to which this asperity is relevant, so we cannot really say if it actually happened on a bending of the main fault as claimed by Bernard and Zollo (1989) or along a continuation of the main fault. 


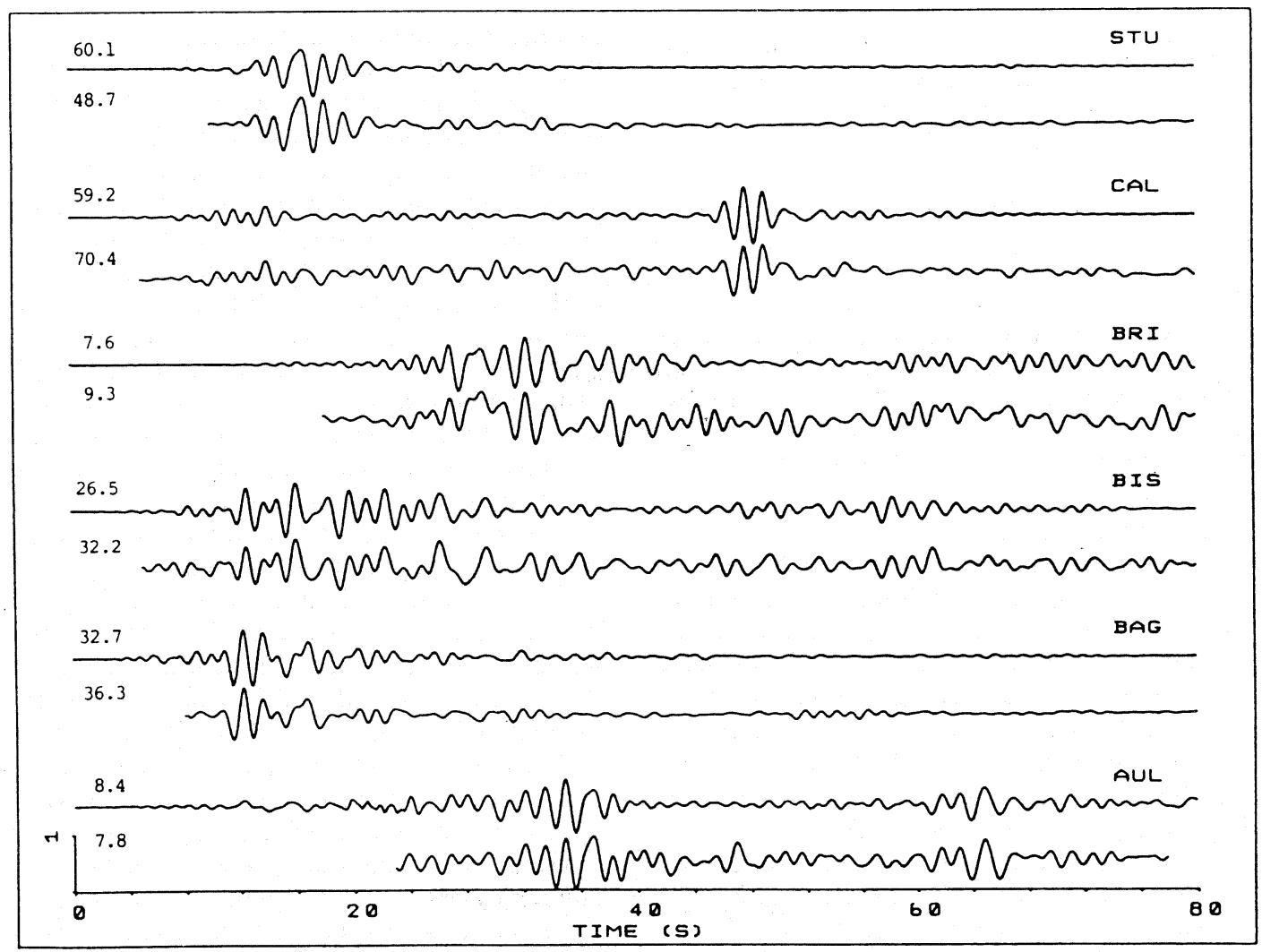

Fig. 8. Synthetic accelerograms (above) and observed ones (below), filtered with a cut-off frequency of 1 $\mathrm{Hz}$. They are shown normalized to their maximum amplitude (expressed in $\mathrm{cm} / \mathrm{s}^{2}$ ).

Since the record shows a strong impulsive signal, we suppose it must have been generated by a short shallow subevent whose wavetrains were quickly scattered and attenuated. The total moment release along the main fault is about $5.6 \times$ $10^{25}$ dyne $\mathrm{cm}$, with an average slip of about 35 $\mathrm{cm}$. The maximum slip along the main asperities is more than $2 \mathrm{~m}$, a rather high value, but not too far away from that predicted by theoretical models (King, 1986) in case of surface displacements of about $1 \mathrm{~m}$, as observed by Pantosti and Valensise (1990).

The second main sub-event, the so-called «20 S» sub-event, probably took place along two different faults. It could have started along a subhorizontal fault to the southeast of the main fault, as proposed by Bernard and Zollo (1989), and then propagated upwards along the continuation of the main fault to the south. In our model the subhorizontal plane has a dip of $20^{\circ}$, but we think that this parameter is not well constrained. The nucleation point is at $40^{\circ} 43^{\prime} 00^{\prime \prime} \mathrm{N}$ and $15^{\circ} 30^{\prime}$ $00^{\prime \prime} \mathrm{E}$, with nucleation time of $15.6 \mathrm{~s}$. The subhorizontal plane is not strictly necessary to explain the main phases at the two southernmost stations, Auletta and Brienza, but is the only way to generate a signal of length comparable to that observed on the two records. It also helps to reproduce the long-period arrivals at Brienza. The presence of the asperities A5, A6 and A7 is a common feature of all the models with a subhorizontal fault, as is the lack of radiation between asperities A5 and A7. We think that this is a real feature since no other asperity could mask this effect. 
The seismic moment released by the subhorizontal fault is about $1 \times 10^{25}$ dyne $\mathrm{cm}$ and that of the subvertical fault is about $2 \times 10^{25}$ dyne $\mathrm{cm}$. The average slip on these faults is $47 \mathrm{~cm}$ and 20 $\mathrm{cm}$, respectively. As far Auletta is concerned, the station was clearly on a radiation minimum with respect to the main event, as pointed out by Vaccari et al. (1990a), but to match its later phases with those of the « 40 s» subevent we need a triggering time of $22 \mathrm{~s}$, a value much higher than that commonly accepted by other authors.

The last sub-event, the so-called «40 s» subevent, is by far the less resolvable. We tried to invert for models with nucleation points corresponding to those proposed by Bernard and Zollo (1989), as well as to a couple of other locations. The only acceptable location seems to be that of their model A $\left(40^{\circ} 52^{\prime} 00^{\prime \prime} \mathrm{N}, 15^{\circ} 21^{\prime} 00^{\prime \prime} \mathrm{E}\right)$. The time shift is $41 \mathrm{~s}$, higher than usually accepted, and the nucleation depth is only $8 \mathrm{~km}$. The fault has a strike of $95^{\circ}$ and a dip of $75^{\circ}$ toward north. The strike is the only well-resolved parameter. The total moment release is too high compared to the dimension of the fault $\left(3 \times 10^{25}\right.$ dyne $\mathrm{cm}$, average slip $40 \mathrm{~cm}$ ) and the nucleation point is not at the bottom of the fault as should be expected. Finally, the actual distribution of the seismic moment along the fault is not realistic, since all the small asperities are spaced in time exactly $1 \mathrm{~s}$ one from the other. The most probable explanation is that the structural model we used does not describe adequately the area sampled by the waves generated by the $40 \mathrm{~s}$ fault. Nevertheless, we believe that our model describes adequately the source mechanism and that any further refinement is probably beyond the resolving power of the accelerograms.

The total estimated seismic moment for the Irpinia earthquake results in $1.13 \times 10^{26}$ dyne $\mathrm{cm}$, compared to the value of $3 \times 10^{26}$ dyne $\mathrm{cm}$ estimated at teleseismic distances. Our extendedfault $M_{0}$ value is related to frequencies around $1 \mathrm{~Hz}$, which are much higher than those used to compute the point-source seismic moment in the teleseismic domain. Since the intensity of the radiation of high-frequency waves is much smaller than that for low-frequency waves (e.g., Gusev, 1983), our estimated seismic moment is about $40 \%$ lower than the teleseismic one.

\section{Modelling of the macroseismic field with synthetic isoseismals}

It seems that Davison (1891) was among the first who tried to infer properties of the causative fault from the analysis of isoseismal lines. Later on the isoseismals were mainly interpreted with empirical laws (e.g., Blake, 1941) for focal depth and intensity attenuation determination, until Shebalin (1972) again suggested to seek in the shape of the isoseismals information on the source geometry.

One of the first very simple methods to compute synthetic isoseismals was proposed by Ohta and Satoh (1980) in order to relate observed isoseismals to source properties. They considered only a half-space and direct rays, and assumed the intensity to be proportional to the average slip on the fault. In such a way, both the orientation of the source and the propagation of seismic waves in more realistic media are neglected and noncircular isoseismals can only be explained by the spatial extension of the fault.

Recently Chiaruttini and Siro (1991) proposed a method, which takes into consideration only the $S$-wave radiation and the directivity effect. They do not consider either realistic media or the propagation of waves through them. To relate their theoretical kinematical function to observed isoseismals, they have to heavily rely on empirical laws relating on the one hand the theoretical kinematical function to observed peak ground acceleration (PGA) values and, on the other hand, PGA values to intensity data.

A method to construct synthetic isoseismals based on the computation of synthetic ground motion has been proposed by Zahradnik (1989). His algorithm, however, takes into account only the direct $S$ wave and is thus able to compute theoretically only the innermost isoseismal.

The possibility of computing complete synthetic signals is a powerful tool for the investigation of source and structural effects on the macroseismic field. The method proposed by Suhadolc et al. (1988b) takes advantage of the computation, for a given source and structural model, of complete synthetic seismograms (Panza, 1985; Panza and Suhadolc, 1987; Florsch et al., 1991) to obtain the maximum ground response at a given point. Originally the method 
was proposed using $\mathrm{SH}$ waves only by Panza and Cuscito (1982).

Synthetic isoseismals are computed by, first, adding vectorially in the horizontal plane, the $\mathrm{SH}$ - and $\mathrm{P}-\mathrm{SV}$-wave displacement fields. The maximum zero-to-peak value of displacement is then calculated at points properly distributed in space, so that it is easy to contour the isolines automatically. A detailed description of the method is given by Panza et al. (1991).

The source process of the November 23, 1980 Irpinia (Southern Italy) earthquake has been studied extensively through the analysis of teleseismic waves (e.g., Deschamps and King, 1983; Westaway and Jackson, 1987), strong ground motion (e.g., Bernard and Zollo, 1989; Vaccari et al., 1990a), levelling data (e.g., Crosson et al., 1986) and by fault mapping (Westaway and Jackson, 1984; Pantosti and Valensise, 1990).

For a cut-off frequency of $0.1 \mathrm{~Hz}$ the pointsource approximation is still acceptable for this M=6.9 event (Suhadolc et al., 1988b; Panza et al., 1991).

The elongation of the isoseismals, parallel to the axis of the Apenninic chain (fig. 9), is thus neatly modeled in this approximation and could be attributed to the point-source parameters

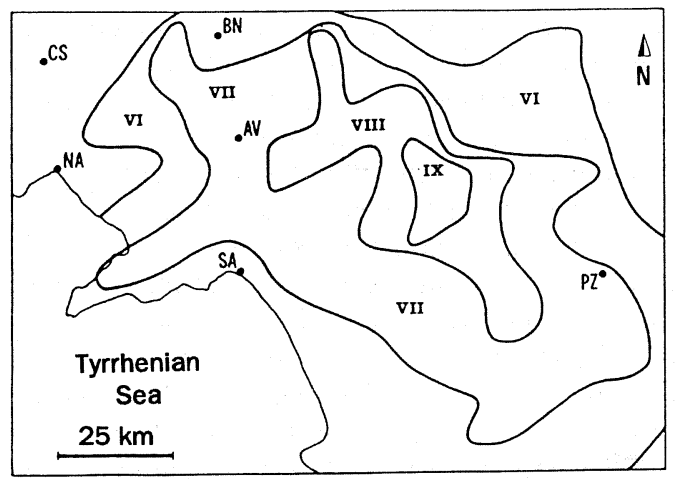

Fig. 9. Observed isoseismals of the November 23, 1980 Irpinia (Southern Italy) earthquake, MSK scale (after Postpischl, private communication). We have chosen to use as experimental data these isolines and not the ones, significantly smoothed, published by CNR (1985) to stress the importance of using, whenever possible, unsmoothed macroseismic fields. $\mathrm{AV}=$ Avellino, $\mathrm{BN}=$ Benevento, $\mathrm{CS}=$ Caserta, $\mathrm{NA}=\mathrm{Na}-$ poli, $\mathrm{SA}=$ Salerno, $\mathrm{PZ}=$ Potenza.

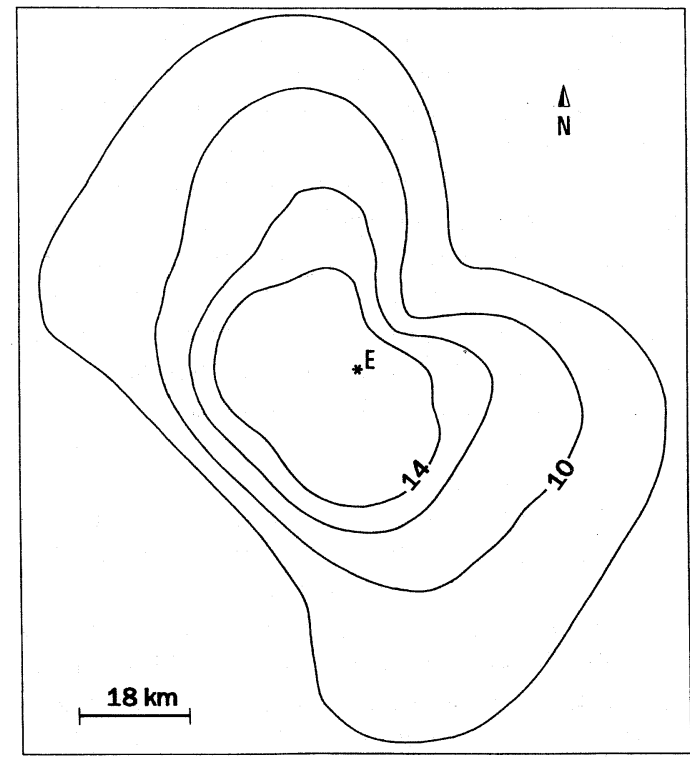

Fig. 10. Theoretical total displacement field (in units of $10^{-29} \mathrm{~m}$ ) for a seismic moment $\left|M_{0}\right|=10^{-7} \mathrm{Nm}$ and a point source at $6-\mathrm{km}$ depth modelling the November 23, 1980 Irpinia earthquake. Cut-off frequency $0.1 \mathrm{~Hz}$.

(fig. 10). The differences between the isoseismals obtained by Panza and Cuscito (1982), who used only $S H$ waves and a focal depth of $18 \mathrm{~km}$, and those computed by Panza et al. (1991) are obviously due to the inclusion, in the latter paper, of the $P-S V$ field. The main effect of the inclusion of the $P-S V$ field is to partly «fill in» the «voids» present in the Panza and Cuscito (1982) solution, which are due to the nodal lines of the $S H$-wave radiation. Moreover, to obtain a radiation dominated by $S H$ waves (i.e. with an Apenninic elongation) the focus has to be moved to around $6 \mathrm{~km}$.

The effect of the variation of the cut-off frequency of seismogram computation on the isoseismal lines has been extensively studied by Suhadolc (1990). In fact, by considering frequencies up to $1 \mathrm{~Hz}$ it has been shown that the singlepoint approximation for the source is not acceptable any more for events of the size of the Irpinia earthquake (fig. 11).

The dimensions and rupturing process of this earthquake (see sect. 1 and 2) make the introduc- 


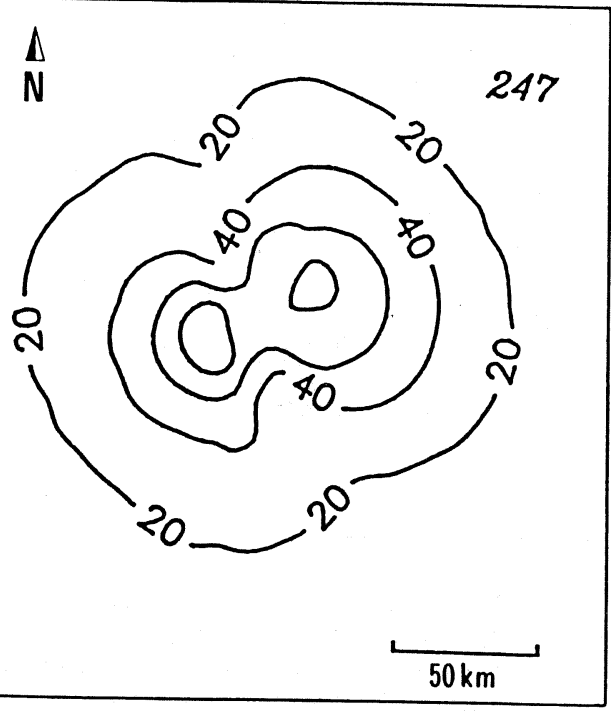

Fig. 11. Normalized total theoretical displacement field for a seismic moment $\left|M_{0}\right|=10^{-7} \mathrm{Nm}$ and a point source at 6-km depth, modelling the November 23, 1980 Irpinia earthquake. Cut-off frequency $1 \mathrm{~Hz}$. The displacement values are normalized to 100 , the maximum value (in units of $10^{-29} \mathrm{~m}$ ) being 247 .

tion of spatially extended sources to model the isoseismal lines at frequencies higher than $0.1 \mathrm{~Hz}$ necessary. The main features of the source process of the Irpinia earthquake described by most of the authors can be reduced to six major subevents whose spatial distribution is shown in fig. 12. Panza et al. (1991) clearly showed that with a cut-off frequency of $0.1 \mathrm{~Hz}$ - the spatial finiteness of the source introduces only minor effects superimposed to those of the single-point source (fig. 13). Using the extended source model of fig. 12 with a cut-off frequency of $1 \mathrm{~Hz}$, on the other hand, produces (Vaccari et al., 1990b) a result (fig. 14) which is totally different from that obtained using a single-point source with the same cut-off frequency (fig. 11), and which reproduces the observations extremely well.

Both Vaccari et al. (1990b) and Panza et al. (1991) used an approximation in the construction of the synthetic isoseismals for an extended source. They considered the highest value of the displacement maxima due to the various point sources at each point of the grid in order to obtain synthetic isoseismals. In this way, however, one neglects the arrival times and interference of different waves. To be more accurate it is necessary to compute and sum at each point of the grid the time series of all the involved point sources and then to consider the maximum values at each point of the grid. This procedure has been then applied to generate the synthetic isoseismals of fig. 15, for the extended source with a cut-off frequency of $1 \mathrm{~Hz}$. Even if no data fitting has been performed, the resulting synthetic isoseismals do explain some of the characteristic features of the observed macroseismic field. At present we do not have a procedure to assess the «similarity» of two macroseismic fields. Probably the result of fig. 15 should be compared with the individual

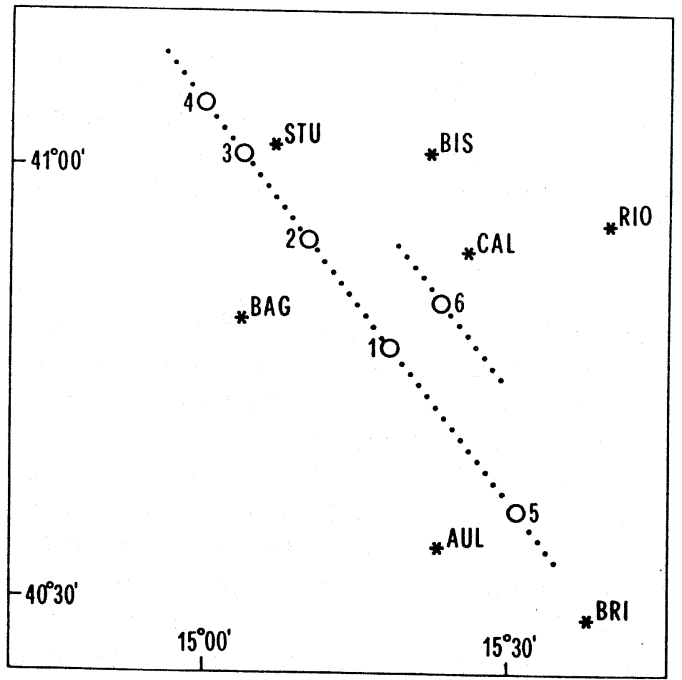

Fig. 12. Epicentral area of the November 23, 1980 Irpinia earthquake. Stars denote the accelerometric stations: Sturno (STU), Rionero in Vulture (RIO), Calitri (CAL), Brienza (BRI), Bisaccia (BIS), Bagnoli Irpino (BAG) and Auletta (AUL). The dotted lines indicate the surface projections of the faults of the model (Harabaglia et al., 1987). The open circles denote the position of the six point sources, whose theoretical isoseismals were used to construct the synthetic isoseismals of fig. 13, 14 and 15 . The fault plane orientation and relative strength of the single-point sources are the following (number of point source, relative strength, strike, dip and rake): 1 - $0.6,320^{\circ}$, $70^{\circ}, 275^{\circ} ; 2-0.8,320^{\circ}, 70^{\circ}, 275^{\circ} ; 3-1.0,340^{\circ}, 90^{\circ}$, $270^{\circ} ; 4-0.7,360^{\circ}, 90^{\circ}, 270^{\circ} ; 5-0.7,320^{\circ}, 70^{\circ}, 275^{\circ}$; $6-0.6,110^{\circ}, 70^{\circ}, 275^{\circ}$. 


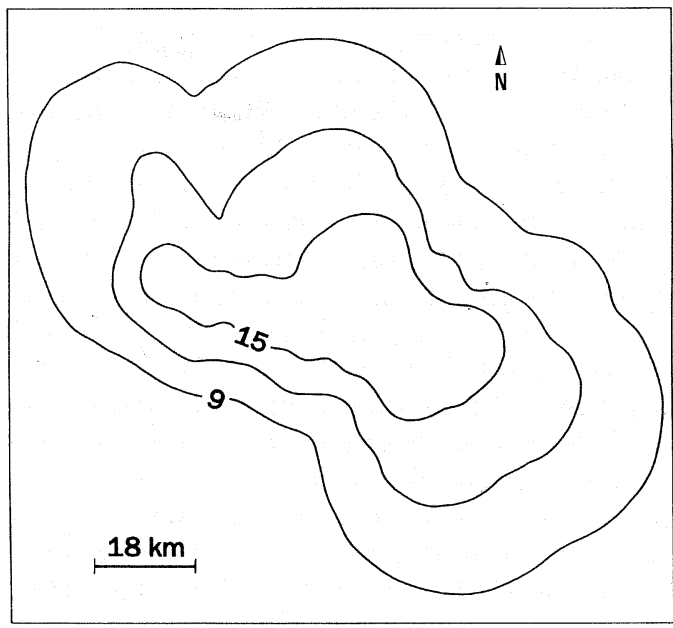

Fig. 13. Theoretical total displacement field (in units of $10^{-29} \mathrm{~m}$ ) for six point sources (see fig. 12) at 6 $\mathrm{km}$ depth, each with a seismic moment $\left|M_{0}\right|=10^{-7} \mathrm{Nm}$, modelling the November 23, 1980 Irpinia earthquake. Cut-off frequency: $0.1 \mathrm{~Hz}$. Approximations introduced (see text).

observed intensity values rather than drawn isolines. At such a stage the deviations from the computed field and the observations can be attributed to local conditions.

Possible influences of the local structural parameters on the shape of the isoseismals are presently under investigation. This is accomplished by computing the synthetic seismograms in 2-D media. Vaccari et al. (1989) developed a technique, based on the normal mode summation, which allows us to take into account different structural properties for the source and receiver region. More recently, Fäh et al. (1990) were able to model in detail the lateral heterogeneities of the receiver region with a hybrid technique combining the normal mode summation with the finite difference method. The application of these 2-D methodologies will allow us, on the one hand, to correct the computation of isoseismals for the effect of major structural discontinuities and, on the other, to model local variations of intensities due to site effects.

In conclusion, a large part of the macroseismic data - let us call it the «regional» trend or longwavelength part of the signal - can be explained

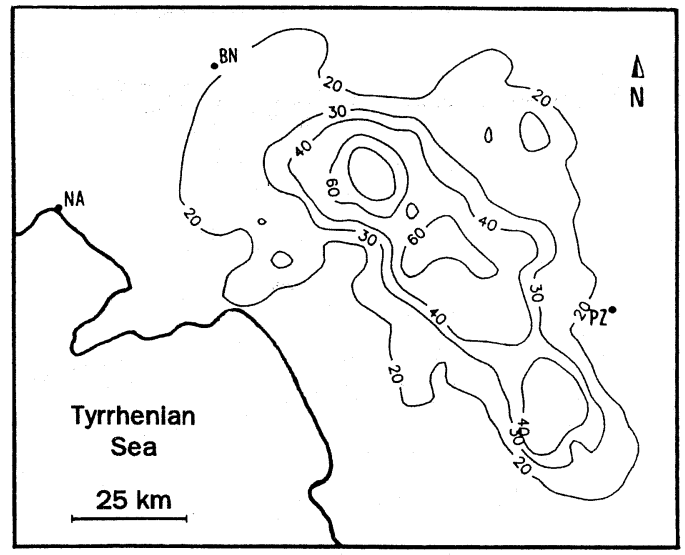

Fig. 14. Normalized total theoretical displacement field for the six point sources of fig. 12 at $6-\mathrm{km}$ depth, each with a seismic moment $\left|M_{0}\right|=10^{-7} \mathrm{Nm}$, modelling the November 23, 1980 Irpinia earthquake. Cut-off frequency $1 \mathrm{~Hz}$. Approximations introduced (see text).

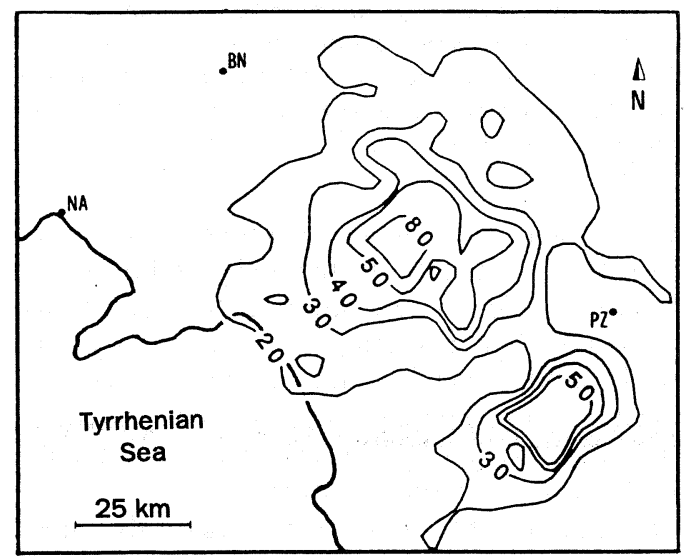

Fig. 15. Normalized total theoretical displacement field for six point sources (see fig. 12) at 6-km depth, each with a seismic moment $\left|M_{0}\right|=10^{-7} \mathrm{Nm}$, modelling the November 23, 1980 Irpinia earthquake. Cut-off frequency $1 \mathrm{~Hz}$.

as due to the source radiation (either in the point or extended source approximations). Structural variations and local site geology can be considered as responsible for second-order effects and, especially the latter, generate in the isoseismals signals with much smaller wavelengths than the ones that can be attributed to the source. That 
this is the case is confirmed also by the fact that in determining the «regional» macroseismic field one makes use of the so-called «group intensities», which effectively smooth out small wavelength intensity variations.

\section{Acknowledgments}

We would like to thank R. M. W. Musson for sending us a copy of the article by $\mathrm{C}$. Davison.

This research has been possible thanks to the following funds: MURST $40 \%$ and $60 \%$; CNRGNDT 89.02015.54; CNR-GNDT 90.01007.54.

\section{REFERENCES}

AKI, K. (1979): Characterization of barriers on an earthquake fault, J. Geophys. Res., 84, 6140-6148.

BERARDI, R., A. BERENZI and F. CAPOZZA (1981): CampaniaLucania earthquake on 23 November 1980: accelerometric recordings of the main quake and relating processing, in Contributo alla caratterizzazione della sismicità italiana (ENEA-ENEL, Roma), pp. 1-103.

BERNARD, P. and A. Zollo (1989): The Irpinia (Italy) 1980 earthquake: detailed analysis of a complex normal faulting, J. Geophys. Res., 94, 1631-1647.

BLAKE, A. (1941): On the estimation of focal depth from macroseismic data, Bull. Seismol. Soc. Am., 31, 225-231.

ChiarutTini, C. and L. Siro (1991): Focal mechanism of an earthquake of Baroque Age in the «Regno delle Due Sicilie» (southern Italy), in Investigation of Historical Earthquakes in Europe, edited by M. STUCCHI, D. PosTPISCHL and D. SLEJKO, Tectonophysics, Vol. 193, pp. 195-203.

Crosson, R.S., M. MARTINI, R. SCARPA and S.C. KEY (1986): The southern Italy earthquake of 23 November 1980: an unusual pattern of faulting, Bull. Seismol. Soc. Am., 76 381-394.

DAVISON, C. (1891): On the Inverness earthquakes of November 15 to December 14, 1890, Q. J. Geol. Soc., 47, 618-632.

DAS, S. and K. AKI (1977): Fault planes with barriers: a versatile earthquake model, J. Geophys. Res., 82, 56585670.

Del Pezzo, E., G. Iannaccone, M. Martini and R. Scarpa (1983): The 23 November 1980 southern Italy earthquake, Bull. Seismol. Soc. Am., 73, 187-200.

Deschamps, A. and G.C.P. KING (1983): The Campania-Lucania (southern Italy) earthquake of 23 November 1980 , Earth Planet. Sci. Lett., 62, 296-304.

FäH, D., P. SUHADOLC and G.F. PANZA (1990): Estimation of strong ground motion in laterally heterogenenous media: modal summation - finite differences, in Proceedings of the 9-th European Conference of Earthquake Engineering, Moscow, September 11-16, 1990, Vol. 4A, pp. 100109.

Florsch, N., D. FÄH, P. SuHAdOLC and G.F. PANZA (1991):
Complete synthetic seismograms for high-frequency multimode Love waves, submitted to $P A G E O P H$.

GuSEv, A.A. (1983): Descriptive statistical model of earthquake source radiation and its application to an estimation of short period strong motion, Geophys. J.R. Astron. Soc. Am., 74, 787-800.

Harabaglia, P., P. Suhadolc and G.F. Panza (1987): Il terremoto irpino del 23.11.1980: meccanismi di rottura dall'inversione di dati accelerometrici, in Atti $6^{\circ}$ Convegno GNGTS, CNR, Roma, pp. 119-124.

KANAMORI, H. and G. STEWART (1978): Seismological aspects of the Guatemala earthquake of February 4, 1976, J. Geophys. Res., 83, 3427-3434.

KING, G. (1986): Speculations on the geometry and termination processes of earthquake rupture and its relation to morphology and geological structure, PAGEOPH, 124, 567-585.

ОнтА, Y. and K. SAтон (1980): Analyses on seismic intensity and earthquake disaster in the Caldiran earthquake, in Engineering Seismological Studies on the 24 November 1976 Caldiran Earthquake in Turkey, edited by Y. OHTA (Dept. Arch. Eng., Hokkaido University, Sapporo), pp. 89-117.

PANTOSTI, D. and G. VAlENSISE (1990): Faulting mechanism and complexity of the November 23, 1980, Campania-Lucania earthquake, J. Geophys. Res., 95, 15319-15342.

PANZA, G.F. (1985): Synthetic seismograms: The Rayleigh waves modal summation, J. Geophys., 58, 125-145.

PANZA, G.F., F. SchWAB and L. KNOPOFF (1973): Multimode surface waves for selected focal mechanisms. I Dip-slip sources on a vertical fault plane, Geophys. J. R. Astron. Soc., 34, 265-278.

PANZA, G.F. and M. Cuscito (1982): Influence of focal mechanism on shape of isoseismals: Irpinia earthquake of November 23, 1980, Pure Appl. Geophys., 120, 577-582.

PANZA, G.F. and P. SuHADOLC (1987): Complete strong motion synthetics, in Seismic Strong Motion Synthetics, Computational Techniques, edited by B.A. BoLt (Academic Press, Orlando), Vol. 4, pp. 153-204.

Panza, G.F., A. Craglietto and P. Suhadolc (1991): Source geometry of historical events retrieved by synthetic isoseismals, in Investigation of Historical Earthquakes in Europe, edited by M. STUCCHI, D. POSTPISCHL and D. SleJKo, Tectonophysics, Vol. 193, pp. 173-184.

Press, W., B. FlanNery, S. TeuKolsKy and W. VeTterling (1986): Numerical Recipes (Cambridge University Press, Cambridge).

SHEBALIN, N.V. (1972): Macroseismic information on source parameters of large earthquakes, Phys. Earth Planet. Inter., 6, 316-323.

Suhadolc, P. (1990): Synthetic isoseismals, Proceedings of the First European School on Seismic Hazard Assessment, Athens, May 9-16, 1988 (in press).

SuHADOLC, P., F. VACCARI and G.F. PANZA (1988a): Strong motion modelling of the rupturing process of the November 23, 1980 Irpinia, Italy, earthquake, in Seismic Hazard in Mediterranean Regions, edited by J. BONNIN, M. CARA, A. Cisternas and R. FANTECHI (Kluwer, Dordrecht), pp. 105-128.

Suhadolc, P., L. Cernobori, G. Pazzi and G.F. Panza (1988b): Synthetic isoseismals: applications to Italian earthquakes, in Seismic Hazard in Metiterranean Re- 
gions, edited by J. BonNIN, M. CARA, A. CISTERnAS and R. FANTECHI (Kluwer, Dordrecht), pp. 105-128.

SuHAdolC, P., P. HARABAGlia and G.F. PANZA (1990): Deterministic modeling and estimate of strong ground motion: the Irpinia, Italy, November 23, 1980 earthquake, in Proceedings of the 9 th European Conference on Earthquake Engineering, Kucherenko Tsniisk, USSR (Gosstroy, Moscow), Vol. 4A, pp. 110-120.

VAcCari, F., S. Gregersen, M. Furlan and G.F. Panza (1989): Synthetic seismograms in laterally heterogeneous anelastic media by modal summation of $P$-SV-waves, Geophys. J. Int., 99, 285-295.

VACCARI, F., P. SUHADOLC and G.F. PANZA (1990a): Irpinia, Italy, 1980 earthquake: waveform modelling of strong motion data, Geophys. J. Int., 101, 631-647.
VACCARI, F., P. SuHADOLC and G.F. PANZA (1990b): Irpinia 1980 earthquake: the rupturing process and the influence of source geometry on the macroseismic field, in Preprints of the Proceedings of the International Meeting «Irpinia Dieci Anni Dopo», Sorrento, November 1990 (Istituto Nazionale di Geofisica), pp. 68-72.

WESTAWAY, R. and J. JACKSON (1984): Surface faulting in the southern Italian Campania-Basilicata earthquake of 23 November 1980, Nature, 312, 436-438.

WESTAWAY, R. and J. JACKSON (1987): The earthquake of 1980 November 23 in Campania-Basilicata (southern Italy), Geophys. J. R. Astron. Soc., 90, 375-443.

ZAHRADNIK, J. (1989): Simple method for combined studies of macroseismic intensities and focal mechanisms, Pure Appl. Geophys., 130, 83-97. 